\section{Chemoenzymatic Preparation of Nucleoside Triphosphates}

This unit presents protocols for the preparation of azole carboxamide deoxyribo- and ribonucleoside triphosphates by enzyme-catalyzed phosphorylation of the cognate diphosphates. The latter are synthesized from nucleoside $5^{\prime}$ - $O$-tosylates by displacement with tris(tetra- $n$-butylammonium) pyrophosphate. Purification procedures using boronate affinity gel to yield highly purified nucleoside triphosphates are also presented.

A general procedure for the preparation of the azole carboxamide deoxyribonucleoside triphosphates is described first (see Basic Protocol 1). This method involves selective 5 -tosylation of the azole carboxamide deoxyribonucleoside, followed by displacement of the $5^{\prime}$-tosylate with tris(tetra- $n$-butylammonium) pyrophosphate to yield the corresponding nucleoside diphosphate. Enzymatic phosphorylation utilizes ATP as the phosphate donor and nucleoside diphosphate kinase as the catalyst, coupled with phosphoenolpyruvate (PEP) and pyruvate kinase as an ATP regeneration system.

Next, a general procedure is presented for the synthesis of azole carboxamide ribonucleoside triphosphates (see Basic Protocol 2). This method includes protection of 2', 3'hydroxyl groups of the ribonucleoside, $5^{\prime}$-tosylation, displacement of the $5^{\prime}$-tosylate with tris(tetra- $n$-butylammonium) pyrophosphate, and deprotection of the $2^{\prime}, 3^{\prime}$-hydroxyls to yield ribonucleoside diphosphate. Enzyme-catalyzed phosphorylation uses PEP as the phosphate donor and pyruvate kinase as the catalyst.

\section{SYNTHESIS OF AZOLE CARBOXAMIDE DEOXYRIBONUCLEOSIDE TRIPHOSPHATES}

This protocol outlines a general procedure for the synthesis and purification of azole carboxamide deoxyribonucleoside triphosphates (Fig. 13.2.1; Wu et al., 2003). Specific instructions are given for the synthesis of $\mathrm{TzA}_{4}$ triphosphate $(\mathbf{S . 1 0})$; however, synthesis of the other azole carboxamide deoxyribonucleoside triphosphates in Figure 13.2.1 (S.11 and S.12) can be accomplished using the same procedure (see Critical Parameters and Troubleshooting).

\section{Materials}

Azole carboxamide deoxyribonucleoside (Fig. 13.2.1): S.1 (N = TzA al., 1977), $\mathbf{S . 2}\left(\mathrm{N}=\mathrm{TzA}_{3}\right.$; Witkowski et al., 1975), or $\mathbf{S . 3}\left(\mathrm{N}=\mathrm{Tz}_{2} \mathrm{~A}_{4}\right.$; Makabe et al., 1977)

Pyridine, anhydrous

Argon

$p$-Toluenesulfonyl chloride (TsCl)

Ethyl acetate, ACS reagent grade

$5 \%(\mathrm{w} / \mathrm{v})$ phosphomolybdic acid solution (see recipe)

Methanol, ACS reagent grade

200- to 400-mesh silica gel 60

Hexanes, ACS reagent grade

Phosphorus pentoxide $\left(\mathrm{P}_{2} \mathrm{O}_{5}\right)$

Dowex AG 50W-X8 cation-exchange resin (100 to 200 mesh, Bio-Rad)

$1 \mathrm{M} \mathrm{HCl}$

Disodium dihydrogen pyrophosphate

$1 \mathrm{M}$ and concentrated $(28 \%)$ ammonium hydroxide $\left(\mathrm{NH}_{4} \mathrm{OH}\right)$

$40 \%(\mathrm{w} / \mathrm{v})$ tetra- $n$-butylammonium hydroxide solution (Aldrich)
BASIC

PROTOCOL 1

Nucleoside

Phosphorylation

and Related

Modifications

\subsection{1}

Supplement 16 


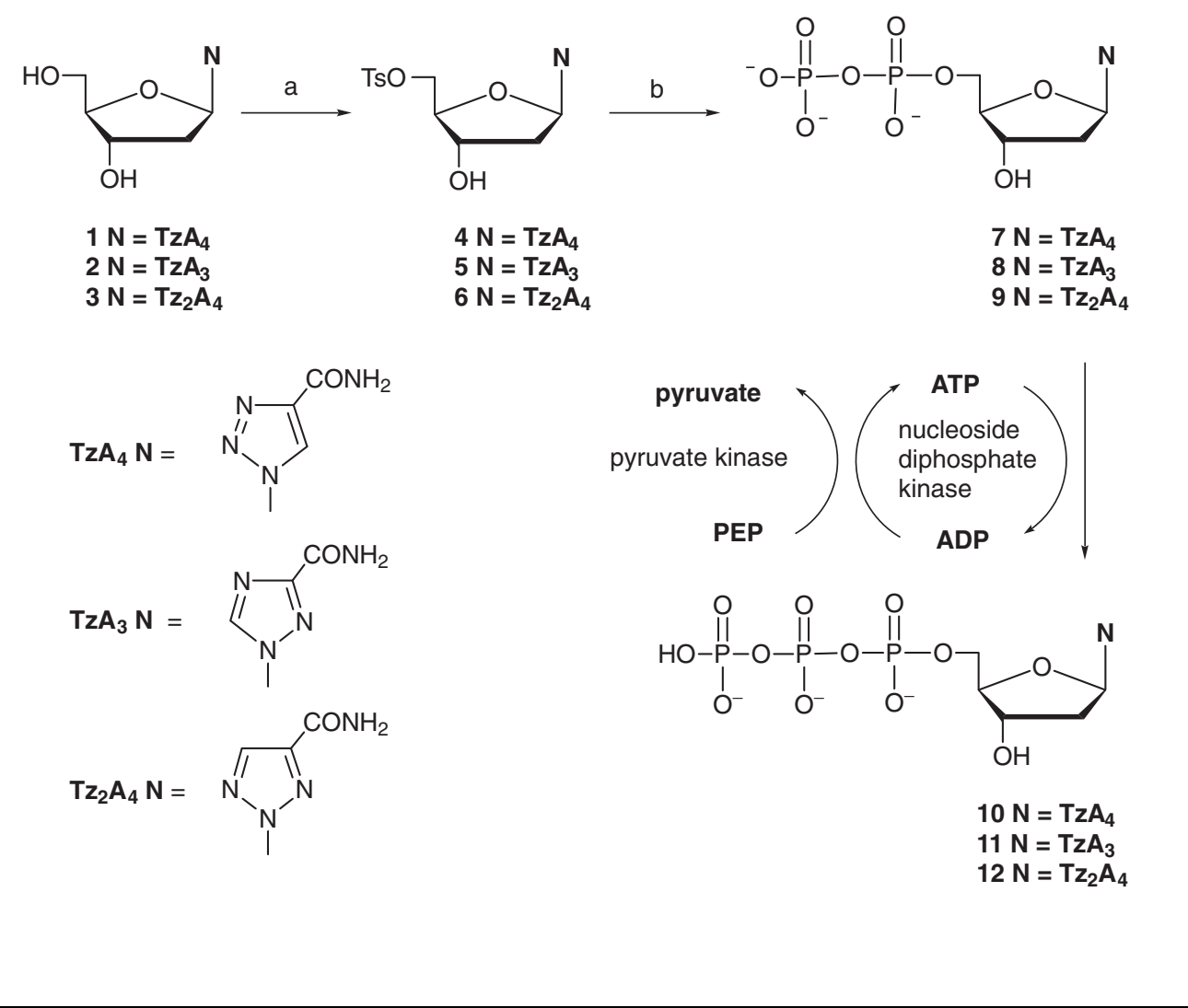

Figure 13.2.1 General procedure for the synthesis of azole carboxamide deoxyribonucleoside triphosphates (see Basic Protocol 1). Reagents: (a) TsCl, pyridine, room temperature (steps 5 and 6); (b) $\left(\mathrm{NBu}_{4}\right)_{3} \mathrm{HP}_{2} \mathrm{O}_{7}, \mathrm{CH}_{3} \mathrm{CN}$, room temperature (steps 27 and 28). Abbreviations: $\mathrm{TzA}_{3},(1 \mathrm{H})$ 1,2,4-triazole-3-carboxamide; $\mathrm{TzA}_{4},(1 H)$-1,2,3-triazole-4-carboxamide; $\mathrm{Tz}_{2} \mathrm{~A}_{4},(2 H)$-1,2,3-triazole4-carboxamide.

Acetonitrile, anhydrous

Deuterated acetonitrile (Aldrich)

CF11 fibrous cellulose powder (Whatman)

$50 \mathrm{mM}, 100 \mathrm{mM}$, and $500 \mathrm{mM}$ ammonium bicarbonate $\left(\mathrm{NH}_{4} \mathrm{HCO}_{3}\right)$ solutions (no $\mathrm{pH}$ adjustment)

$1 \%(\mathrm{w} / \mathrm{v})$ sulfosalicylic solution (see recipe)

$0.2 \%(\mathrm{w} / \mathrm{v})$ ferric chloride solution (see recipe)

Triethanolamine hydrochloride (Sigma)

Magnesium chloride hexahydrate $\left(\mathrm{MgCl} \cdot 6 \mathrm{H}_{2} \mathrm{O}\right)$

Potassium chloride $(\mathrm{KCl})$

Adenosine triphosphate (ATP, disodium salt, Sigma)

Sodium phosphoenolpyruvate monohydrate (PEP; Sigma)

$1 \mathrm{M}$ sodium hydroxide $(\mathrm{NaOH})$

Nucleoside diphosphate kinase (see recipe)

Pyruvate kinase (see recipe)

Mobile phase A: $0.1 \mathrm{M}$ potassium phosphate buffer ( $\mathrm{pH} 6.0 ;$ APPENDIX 2A) containing $4 \mathrm{mM}$ tetrabutylammonium dihydrogenphosphate (TBAP, Aldrich; added from a $1.0 \mathrm{M}$ stock)

Penzymatic

Preparation of

Nucleoside

Triphosphates

Mobile phase B: 70:30 (v/v) mobile phase A/methanol, pH 7.2

Adenosine diphosphate (ADP, sodium salt, Sigma) 
Affi-Gel 601 boronate affinity gel (Bio-Rad)

$1 \mathrm{M}$ ammonium bicarbonate $\left(\mathrm{NH}_{4} \mathrm{HCO}_{3}\right), \mathrm{pH} 8.5$ (see recipe)

Carbon dioxide source (e.g., dry ice)

Q Sepharose FF anion-exchange resin (Bio-Rad)

$1 \mathrm{M}$ potassium chloride $(\mathrm{KCl})$

10- and 20-mL oven-dried one-neck round-bottom flasks with rubber septa

Rotary evaporator equipped with a water aspirator and a temperature-controlled water bath $\left(45^{\circ} \mathrm{C}\right)$

Capillary tubes

TLC plates:

Silica gel $60 \mathrm{~F}_{254}$ polyester-backed TLC plates (Aldrich)

Cellulose TLC plates (EM Science)

Heat gun

254-nm UV lamp

$2.0 \times 25-\mathrm{cm}, 2.5 \times 5-\mathrm{cm}, 2.5 \times 10-\mathrm{cm}, 2.5 \times 20-\mathrm{cm}$, and $2.5 \times 25-\mathrm{cm}$

chromatography columns

Vacuum desiccator

250-mL and 1-L beakers

250-mL round-bottom flasks

Lyophilizer

TLC sprayer (Analtech)

15-mL polystyrene round-bottom tube

HPLC system (e.g., Beckman System Gold) including:

128 solvent module

166 detector set at $230 \mathrm{~nm}$

$25-\mathrm{cm} \times 4.6-\mathrm{mm} \times 5-\mu \mathrm{m}$-i.d. Supelcosil LC-18-T column

25-mm-diameter, 0.2- $\mu$ m nylon syringe filter (Fisher)

Peristaltic pump

Medium-pressure liquid chromatography (MPLC) system (e.g., ISCO LC system)

with following equipment:

Model 2360 gradient programmer

Model 2350 HPLC pump

$\mathrm{V}^{4}$ variable wavelength absorbance detector

Additional reagents and equipment for thin-layer chromatography (TLC, APPENDIX $3 D$ ), column chromatography (APPENDIX $3 E$ ), and ${ }^{1} \mathrm{H}$ NMR, ${ }^{13} \mathrm{C}$ NMR, ${ }^{31} \mathrm{P}$ NMR, and ESI-MS

NOTE: All the nucleosides used in the reaction are dried under reduced pressure ( 0.1 Torr) in the presence of phosphorus pentoxide at $50^{\circ} \mathrm{C}$ in an Abderhalden drying apparatus (Ace Glass) overnight prior to reaction.

\section{Prepare 5'-tosylate of $\mathrm{TzA}_{4}$ deoxyribonucleoside (S.4)}

1. Add $100 \mathrm{mg}(0.44 \mathrm{mmol}) \mathrm{TzA}_{4}$ azole carboxamide deoxyribonucleoside (S.1) to an oven-dried $20-\mathrm{mL}$ one-neck round-bottom flask.

2. Add $5 \mathrm{~mL}$ anhydrous pyridine to the flask and evaporate to dryness with a $45^{\circ} \mathrm{C}$ rotary evaporator equipped with a water aspirator. Repeat this procedure three times.

3. Put a magnetic stir bar into the reaction flask, insert a rubber septum, and place the flask on top of a magnetic stir plate.

4. Evacuate the reaction flask using a vacuum line, then flush with argon. Repeat this procedure three times, then attach the flask to an argon line.

Nucleoside

Phosphorylation and Related Modifications

13.2.3

Supplement 16 
5. Quickly remove the septum, add $100 \mathrm{mg}(0.53 \mathrm{mmol}) \mathrm{TsCl}$ into the reaction flask, and immediately reinsert the septum.

6. Transfer $4 \mathrm{~mL}$ anhydrous pyridine to the flask under argon and stir the reaction at room temperature.

7. Monitor the progress of the reaction by analytical TLC (APPENDIX 3D) as follows:

a. Withdraw a small sample using a capillary tube and spot on a silica gel $60 \mathrm{~F}_{254}$ polyester-backed TLC plate.

b. To remove pyridine in the sample, heat the plate for several minutes using a heat gun until the diffuse dark spot visualized under a 254-nm UV lamp disappears. Be careful not to burn the TLC plate (the polymer will begin to shrink).

It is very important to remove pyridine as completely as possible to allow visualization of the product.

c. Develop the TLC plate in ethyl acetate.

d. Visualize by dipping the plate into $5 \%$ phosphomolybdic acid solution and heating with a heat gun.

The starting material and product appear as blue or dark blue spots on a green background $\left(R_{f}=0.30\right.$ for $\mathbf{S . 1} ; R_{f}=0.50$ for $\left.\mathbf{S . 4}\right)$.

\section{Workup and purify $S .4$}

8. When TLC analysis indicates the reaction is complete ( $\sim 4$ days), remove the magnetic stir bar from the flask and remove the solvent under reduced pressure with a rotary evaporator.

9. Add $10 \mathrm{~mL}$ methanol to the flask and evaporate to dryness. Repeat this procedure three times to completely remove pyridine.

10. Dissolve the obtained residue in $10 \mathrm{~mL}$ methanol and add $1.5 \mathrm{~g}$ of 200 - to 400 -mesh silica gel 60 to the solution. Evaporate the mixture to dryness.

The crude product is absorbed on silica gel.

11. Pack a $2.0 \times 25-\mathrm{cm}$ chromatography column with $25 \mathrm{~g}$ silica gel in $1: 1(\mathrm{v} / \mathrm{v})$ hexanes/ethyl acetate for flash column chromatography (APPENDIX $3 E$ ).

12. Add the silica gel containing the crude product to the top of the packed column.

13. Elute with a stepwise gradient of 1:1 hexanes/ethyl acetate to $100 \%$ ethyl acetate. Collect $10-\mathrm{mL}$ fractions and analyze by TLC as described in step 7.

14. Combine the product-containing fractions and evaporate to dryness with a rotary evaporator.

15. Dry the product overnight over phosphorus pentoxide in a vacuum desiccator at 0.1 Torr.

16. Confirm the desired product by ${ }^{1} \mathrm{H}$ NMR, ${ }^{13} \mathrm{C}$ NMR, and ESI-MS.

Flash chromatography gives $105 \mathrm{mg}$ (62\%) S.4 as a white solid. ${ }^{1} \mathrm{H}$ NMR (DMSO-d, 300 $\mathrm{MHz}): 8.59(1 \mathrm{H}, \mathrm{s}), 7.88(1 \mathrm{H}, \mathrm{s}), 7.68(2 \mathrm{H}, \mathrm{d}), 7.52(1 \mathrm{H}, \mathrm{s}), 7.39(2 \mathrm{H}, d), 6.37(1 \mathrm{H}, t, \mathrm{~J}=$ $6.0 \mathrm{~Hz}), 5.58\left(1 \mathrm{H}, \mathrm{d}, \mathrm{D}_{2} \mathrm{O}\right.$ exchangeable $), 4.38(1 \mathrm{H}, \mathrm{m}), 4.20(1 \mathrm{H}, \mathrm{m}), 4.03(2 \mathrm{H}, \mathrm{m}), 2.64$ $(1 \mathrm{H}, \mathrm{m}), 2.40(4 \mathrm{H}, \mathrm{m}) .{ }^{13} \mathrm{C} \mathrm{NMR}$ (DMSO-d, $\left.75 \mathrm{MHz}\right): 161.3,145.0,143.1,130.1,127.5$, 125.5, 88.0, 84.3, 70.1, 69.9, 21.1. MS (ESI): $383[\mathrm{M}+\mathrm{H}]^{+}$. Anal. calcd. for $\mathrm{C}_{15} \mathrm{H}_{18} \mathrm{O}_{6} \mathrm{~N}_{4} \mathrm{~S}$ : C 47.11, H 4.74, N 14.65; found: C 47.00, H 4.64, N 14.52.

Characterization data for $\mathbf{S . 5}$ and $\mathbf{S . 6}$ can be found in Wu et al. (2003). Nucleoside 
17. Pack Dowex AG 50W-X8 cation-exchange resin in water into a $2.5 \times 10-\mathrm{cm}$ column and elute the column in sequence with $150 \mathrm{~mL}$ of $1 \mathrm{M} \mathrm{HCl}$ and $150 \mathrm{~mL}$ water.

The cation-exchange resin is transformed to the hydrogen form.

18. Dissolve $3.33 \mathrm{~g}$ ( $15.0 \mathrm{mmol})$ disodium dihydrogen pyrophosphate in $13.5 \mathrm{~mL}$ water and $1.5 \mathrm{~mL}$ concentrated $(28 \%)$ aqueous ammonium hydroxide.

19. Pass the solution through the cation-exchange column.

20. Elute the column with $100 \mathrm{~mL}$ deionized water and collect the eluent in a $250-\mathrm{mL}$ beaker.

21. Titrate the eluent to $\mathrm{pH} 7.3$ with $40 \%$ (w/w) aqueous tetra- $n$-butylammonium hydroxide $(\sim 50 \mathrm{~mL})$.

The resulting solution is $\sim 150 \mathrm{~mL}$ in total volume.

22. Transfer the solution to a $250-\mathrm{mL}$ round-bottom flask and lyophilize for $24 \mathrm{hr}$ to dry.

After lyophilization, $13.1 \mathrm{~g}$ (97\%) of a hygroscopic white solid is obtained. The product can be stored up to one year in a desiccator at $-20^{\circ} \mathrm{C}$.

\section{Prepare nucleoside diphosphate S.7}

23. Add $214 \mathrm{mg}(0.56 \mathrm{mmol})$ nucleoside $5^{\prime}$-tosylate $(\mathbf{S . 4})$ to an oven-dried $10-\mathrm{mL}$ one-neck round-bottom flask.

24. Add $5 \mathrm{~mL}$ anhydrous acetonitrile to the flask and evaporate to dryness with a rotary evaporator. Repeat this procedure three times.

25. Put a magnetic stir bar into the reaction flask, insert a rubber septum, and place the flask on top of a magnetic stir plate.

26. Evacuate the reaction flask via a vacuum line, then flush with argon. Repeat this procedure three times and attach the flask to an argon line.

27. Quickly remove the septum, add $1.0 \mathrm{~g}(1.12 \mathrm{mmol})$ tris(tetra- $n$-butylammonium) hydrogen pyrophosphate (step 22) into the reaction flask, and immediately reinsert the septum.

28. Transfer $1.5 \mathrm{~mL}$ anhydrous acetonitrile to the flask under argon and stir the reaction at room temperature.

29. Monitor the progress of the reaction by ${ }^{1} \mathrm{H}$ NMR as follows:

a. Withdraw $50 \mu \mathrm{L}$ reaction mixture and dilute with $0.5 \mathrm{~mL}$ deuterated acetonitrile.

b. Transfer the sample to a dried NMR tube and acquire a ${ }^{1} \mathrm{H}$ NMR spectrum.

c. Monitor the progress of the reaction by the change in the ${ }^{1} \mathrm{H}$ NMR spectrum between 7 and 9 ppm, where the tosylate moiety appears as an $\mathrm{AA}^{\prime} \mathrm{XX}^{\prime}$ spin system.

The four-line pattern for the tosylate moves upfield by 0.1 to $0.2 \mathrm{ppm}$ upon conversion to the tosylate anion.

$T L C$ is not suitable for monitoring the progress of the reaction because the tetra-n-butylammonium salt does not give a well-defined spot.

Nucleoside

Phosphorylation

and Related

Modifications

13.2.5

Supplement 16 
Workup and purify $S .7$

30. When the ${ }^{1} \mathrm{H}$ NMR indicates that the reaction is complete $(\sim 24 \mathrm{hr})$, add $5 \mathrm{~mL}$ deionized water to the reaction mixture.

31. Pack Dowex AG 50W-X8 cation-exchange resin in water into a $2.5 \times 10-\mathrm{cm}$ column. Transform the cation-exchange resin to the ammonium form by washing the column with $150 \mathrm{~mL}$ ( 3 column volumes) of the following solutions in sequence:
$1 \mathrm{M} \mathrm{HCl}$
$\mathrm{H}_{2} \mathrm{O}$
$1 \mathrm{M} \mathrm{NH}_{4} \mathrm{OH}$
$\mathrm{H}_{2} \mathrm{O}$.

32. Load the sample solution from step 30 onto the column.

33. Elute with $100 \mathrm{~mL}$ ( 2 column volumes) water and collect in a $250-\mathrm{mL}$ round-bottom flask. Lyophilize to dryness.

The ${ }^{l} H$ NMR spectrum of the crude product shows only a trace of the signals from the tetra-n-butylammonium cation.

34. Pack a Whatman CF11 fibrous cellulose column as follows:

a. Mix $500 \mathrm{~mL}$ (dry volume) CF11 fibrous cellulose power with $350 \mathrm{~mL}$ water in a 1 - L beaker by vigorous stirring with a glass rod.

b. Slurry-pack the cellulose into a $2.5 \times 25-\mathrm{cm}$ chromatography column.

c. Wash the column with $300 \mathrm{~mL}$ water, $300 \mathrm{~mL}$ acetonitrile, and $300 \mathrm{~mL}$ of $1: 1(\mathrm{v} / \mathrm{v})$ acetonitrile/water in sequence.

d. Equilibrate the column with $300 \mathrm{~mL}$ of 7:3:2 (v/v/v) acetonitrile/100 $\mathrm{mM}$ ammonium bicarbonate/concentrated (28\%) ammonium hydroxide.

35. Extract the crude product (from step 33) with $5 \mathrm{~mL}$ of the same acetonitrile/ammonium bicarbonate/ammonium hydroxide buffer. Pellet the precipitate.

The product is soluble in the buffer and the white precipitate formed is excess inorganic pyrophosphate.

36. Load the soluble material onto the cellulose column and elute with the same buffer by flash chromatography, collecting $10-\mathrm{mL}$ fractions.

37. Analyze every second fraction on a cellulose TLC plate as follows:

a. Spot the sample on the cellulose TLC plate and develop in 7:3:2 acetonitrile/100 $\mathrm{mM}$ ammonium bicarbonate/concentrated ammonium hydroxide.

b. Spray the plate with $1 \%$ sulfosalicylic acid solution until thoroughly wetted but not dripping, and allow to air dry $5 \mathrm{~min}$.

c. Lightly spray $0.2 \%$ ferric chloride solution onto the plate and visualize the spots. When visualized by sulfosalicylic acid/ferric chloride spray, phosphate-containing compounds appear as white spots on a pink background. A second light spray with ferric chloride may be necessary to make the spots pronounced. For $S .7$, the $R_{f}$ value is 0.2 and is similar to the other nucleoside diphosphates.

38. Combine the product-containing fractions and remove acetonitrile by rotary evaporation with the bath temperature below $30^{\circ} \mathrm{C}$.

39. Lyophilize the resulting aqueous solution to dryness.

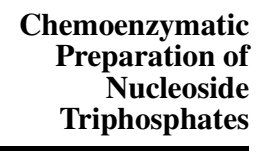

13.2.6 
40. Confirm the product by ${ }^{1} \mathrm{H}$ NMR, ${ }^{13} \mathrm{C}$ NMR, ${ }^{31} \mathrm{P}$ NMR, and ESI-MS.

Flash cellulose chromatography gives $200 \mathrm{mg}(81 \%) \mathrm{S.7}$ as a white fluffy powder. ${ }^{1} \mathrm{H} \mathrm{NMR}$ $\left(D_{2} \mathrm{O}, 300 \mathrm{MHz}\right): 8.68(1 \mathrm{H}, \mathrm{s}), 6.43(1 \mathrm{H}, t, \mathrm{~J}=6.0 \mathrm{~Hz}), 4.14(1 \mathrm{H}, \mathrm{m}), 3.98(2 \mathrm{H}, \mathrm{m}), 2.68$ $(1 \mathrm{H}, \mathrm{m}), 2.52(1 \mathrm{H}, \mathrm{m}) .{ }^{13} \mathrm{C} \mathrm{NMR}\left(\mathrm{D}_{2} \mathrm{O}, 75 \mathrm{MHz}\right): 164.5,141.9,125.9,89.5,86.7,70.6$, 64.9, 39.9. ${ }^{31} \mathrm{P} N M R\left(\mathrm{D}_{2} \mathrm{O}, 121 \mathrm{MHz}\right):-9.85\left(\mathrm{~d}, \mathrm{~J}_{p, p}=21.8 \mathrm{~Hz}\right),-13.38\left(\mathrm{~d}, \mathrm{~J}_{p, p}=21.8 \mathrm{~Hz}\right)$. HRMS (ESI): calcd. for $\mathrm{C}_{8} \mathrm{H}_{15} \mathrm{~N}_{4} \mathrm{O}_{10} \mathrm{P}_{2} 389.0263$ [M+H] $]^{+}$; found 389.0247 .

Characterization data for $\mathbf{S . 8}$ and $\mathbf{S . 9}$ can be found in Wu et al. (2003).

\section{Perform enzyme phosphorylation}

41. Dissolve the following in $8 \mathrm{~mL}$ water in a $15-\mathrm{mL}$ polystyrene round-bottom tube:

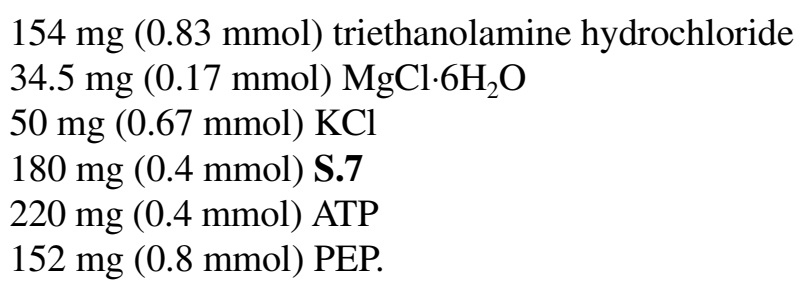

42. Adjust to $\mathrm{pH} 7.6$ with $1 \mathrm{M} \mathrm{NaOH}$, then add water to make the final volume $10 \mathrm{~mL}$.

43. Add $50 \mu \mathrm{L}(100 \mathrm{U})$ nucleoside diphosphate kinase and $80 \mu \mathrm{L}$ ( $200 \mathrm{U}$ ) pyruvate kinase. Incubate the reaction mixture at $37^{\circ} \mathrm{C}$.

44. Monitor the progress of the reaction by analytical HPLC. Take $2-\mu \mathrm{L}$ aliquots, dilute with mobile phase A, and run on a Supelcosil LC-18-T column at a flow rate of 1.5 $\mathrm{mL} / \mathrm{min}$ using the following gradient conditions:

$0 \%$ to $100 \%$ mobile phase B over $10 \mathrm{~min}$

$100 \%$ mobile phase $\mathrm{B}$ for 8 min

$100 \%$ to $0 \%$ mobile phase $\mathrm{B}$ over $2 \mathrm{~min}$.

The retention times of $T z A_{4} D P(S .7)$ and $T z A_{4} T P(S .10)$ should be $\sim 7.7$ and $\sim 10.4 \mathrm{~min}$, respectively. The retention time of $P E P$ should be $\sim 3.8 \mathrm{~min}$.

Special care should be taken to prevent the column from being damaged by the ion-pairing reagent TBAP. The column should first be washed with an adequate volume $(\geq 10$ column volumes) of buffer $A$ without TBAP, then with pure water ( $\geq 10$ column volumes) before equilibrating the column with organic solvent (i.e., $\mathrm{MeOH}$ ) for storage at room temperature.

45. After $\mathbf{S . 7}$ is completely converted to triphosphate $\mathbf{S . 1 0}(\sim 4 \mathrm{hr})$, add $180 \mathrm{mg}(0.4 \mathrm{mmol})$ ADP to the mixture and continue to incubate at $37^{\circ} \mathrm{C}$.

46. Monitor the consumption of PEP by HPLC as described in step 44.

47. Once the excess PEP is completely consumed, pass the mixture through a $25-\mathrm{mm}-$ diameter $0.2-\mu \mathrm{m}$ nylon syringe filter and lyophilize the filtrate to dryness.

\section{Purify S.10 on a boronate affinity gel column}

48. Mix 5 g Affi-Gel 601 boronate affinity gel with water and slurry-pack into a $2.5 \times$ 5-cm column.

49. Equilibrate the column with $100 \mathrm{~mL}$ of $1 \mathrm{M}$ ammonium bicarbonate, $\mathrm{pH} 8.5$.

50. Dissolve the residual solid from step 47 in $10 \mathrm{~mL}$ of $1 \mathrm{M}$ ammonium bicarbonate, $\mathrm{pH} 8.5$, and load the sample solution onto the boronate affinity gel column using a peristaltic pump set at $1 \mathrm{~mL} / \mathrm{min}$.

Alternatively, sample loading and column elution can be done by gravity.

Nucleoside Phosphorylation and Related Modifications

\subsection{7}

Supplement 16 
51. Elute the column with the same buffer using a peristaltic pump set at $1 \mathrm{~mL} / \mathrm{min}$, with UV detection at $230 \mathrm{~nm}$.

52. Collect and pool the fractions containing product in the first two column volumes. Bubble carbon dioxide into the solution until the $\mathrm{pH}$ reaches 7.2.

Carbon dioxide may be conveniently generated from dry ice in a filtering flask with a stopper and a side hose outlet.

53. Lyophilize the solution to dryness. Dissolve in $50 \mathrm{~mL}$ water, adjust to $\mathrm{pH} 7.2$ with carbon dioxide, and repeat lyophilization.

Two or three lyophilization cycles may be required to completely remove excess ammonium bicarbonate.

\section{Purify S.10 on a $Q$ Sepharose FF anion-exchange column}

54. Pack a $2.5 \times 20-\mathrm{cm}$ Q Sepharose FF anion-exchange column and elute with the following using a peristaltic pump at $5 \mathrm{~mL} / \mathrm{min}$ :

$$
\begin{aligned}
& 300 \mathrm{~mL} 1 \mathrm{M} \mathrm{KCl} \\
& 300 \mathrm{~mL} \mathrm{H}_{2} \mathrm{O} \\
& 300 \mathrm{~mL} 50 \mathrm{mM} \text { ammonium bicarbonate solution. }
\end{aligned}
$$

55. Connect the column to an MPLC system equipped with a programmable gradient pump system and a UV detector.

56. Dissolve the solid from step 53 in $10 \mathrm{~mL}$ of $50 \mathrm{mM}$ ammonium bicarbonate solution and load the sample solution onto the column.

57. Elute the column with a linear gradient from $50 \mathrm{mM}$ ammonium bicarbonate to 500 $\mathrm{mM}$ ammonium bicarbonate over $2 \mathrm{hr}$ at a flow rate of $5 \mathrm{~mL} / \mathrm{min}$, with UV detection at $230 \mathrm{~nm}$.

58. Analyze the appropriate fractions by HPLC as described in step 44.

59. Combine fractions containing triphosphate $\mathbf{S . 1 0}$ and lyophilize to dryness.

60. Confirm the product by ${ }^{1} \mathrm{H} \mathrm{NMR},{ }^{13} \mathrm{C} \mathrm{NMR},{ }^{31} \mathrm{P}$ NMR, and ESI-MS.

The final product, $T z A_{4} T P$ S.10 (ammonium salt), is obtained as a white fluffy powder with a yield of $120 \mathrm{mg}$ or $58 \% .{ }^{1} \mathrm{H} \mathrm{NMR}\left(\mathrm{D}_{2} \mathrm{O}, 300 \mathrm{MHz}\right): 8.64(1 \mathrm{H}, \mathrm{s}), 6.42(1 \mathrm{H}, \mathrm{t}, \mathrm{J}=6.0 \mathrm{~Hz})$, $4.14(1 \mathrm{H}, \mathrm{m}), 4.01(2 \mathrm{H}, \mathrm{m}), 2.68(1 \mathrm{H}), 2.50(1 \mathrm{H}, \mathrm{m}) .{ }^{13} \mathrm{C} \mathrm{NMR}\left(\mathrm{D}_{2} \mathrm{O}, 75 \mathrm{MHz}\right): 164.5$, 141.9, 125.9, 89.5, 86.6, 70.4, 65.2, 39.9. ${ }^{31} \mathrm{P} \mathrm{NMR}\left(\mathrm{D}_{2} \mathrm{O}, 121 \mathrm{MHz}\right):-6.26\left(d, J_{p, p}=19.4\right.$ $\mathrm{Hz}),-10.97\left(d, J_{p, p}=19.4 \mathrm{~Hz}\right),-21.88\left(t, J_{p, p}=19.4 \mathrm{~Hz}\right)$. HRMS (ESI): calcd. for $\mathrm{C}_{8} \mathrm{H}_{14} \mathrm{~N}_{4} \mathrm{O}_{13} \mathrm{P}_{3} 466.9770$ [M-H]'; found 466.9766.

Characterization data for $\mathbf{S . 1 1}$ and $\mathbf{S . 1 2}$ can be found in Wu et al. (2003).

BASIC PROTOCOL 2

\footnotetext{
Chemoenzymatic

Preparation of Nucleoside Triphosphates
}

13.2.8

\section{SYNTHESIS OF AZOLE CARBOXAMIDE RIBONUCLEOSIDE TRIPHOSPHATES}

This protocol outlines a general procedure for the synthesis and purification of the azole carboxamide ribonucleoside triphosphate (Fig. 13.2.2; Wu et al., 2003). Specific protocols are given for the synthesis of $\mathrm{rTz}_{2} \mathrm{~A}_{4}$ nucleoside triphosphate (S.19). Synthesis of the other azole carboxamide ribonucleoside triphosphate in Figure 13.2.2 (S.20) can be accomplished using the same procedure (see Critical Parameters and Troubleshooting). 


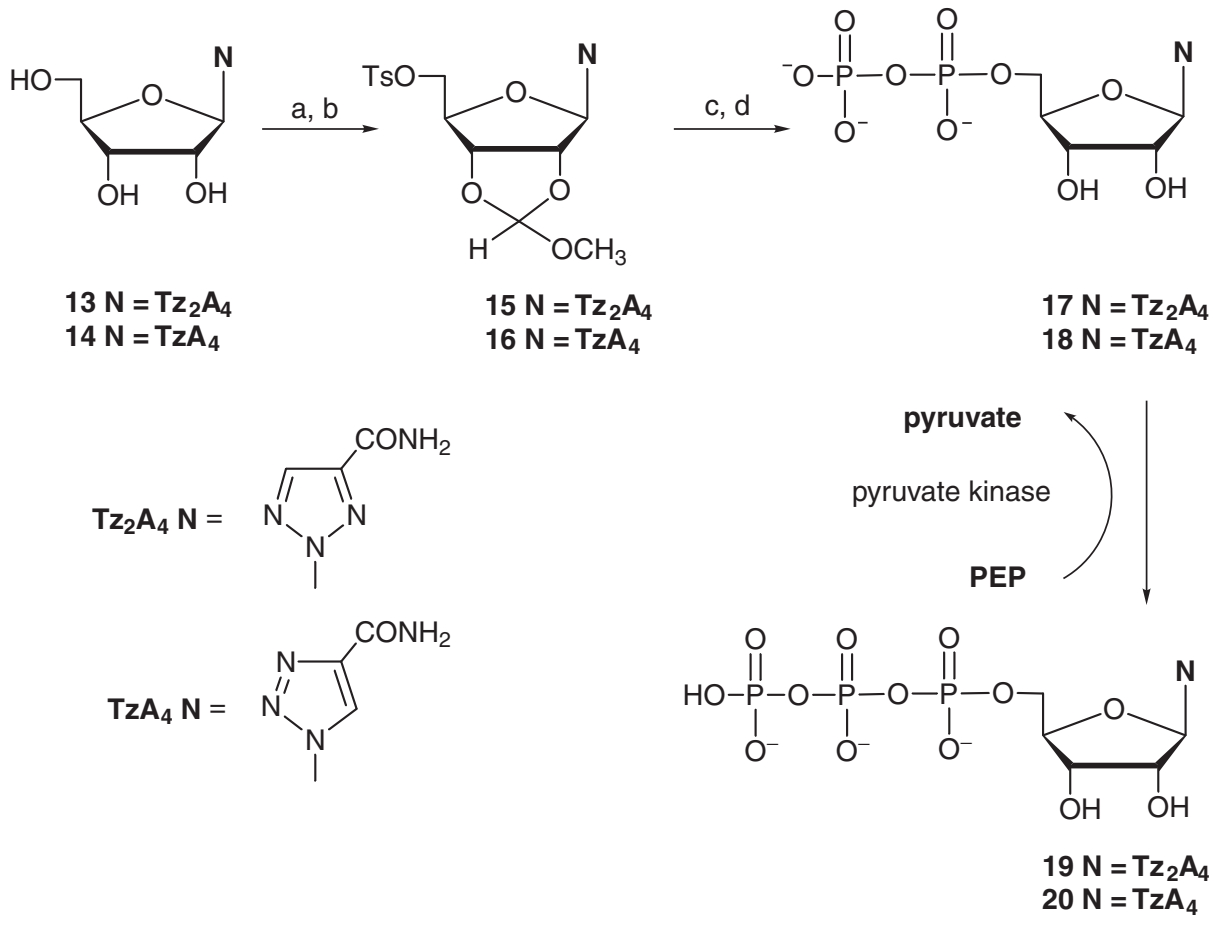

Figure 13.2.2 General procedure for the synthesis of azole carboxamide ribonucleoside triphosphates (see Basic Protocol 2). Reagents: (a) $\left(\mathrm{CH}_{3} \mathrm{O}\right)_{3} \mathrm{CH}, \mathrm{TsOH}, \mathrm{THF}$, room temperature (steps 1 and 2); (b) $\mathrm{TsCl}$, DMAP, $\mathrm{CH}_{2} \mathrm{Cl}_{2}$, room temperature (steps 6 and 7); (c) $\left(\mathrm{NBu}_{4}\right)_{3} \mathrm{HP}_{2} \mathrm{O}_{7}, \mathrm{CH}_{3} \mathrm{CN}$, room temperature (steps 25 and 26); (d) TFA/ $\mathrm{H}_{2} \mathrm{O}, \mathrm{pH} 2.0$, then $\mathrm{NH}_{4} \mathrm{OH} / \mathrm{H}_{2} \mathrm{O}, \mathrm{pH} 8.5$ (steps 28 and 29). Abbreviations: $\mathrm{TzA}_{4},(1 H)$-1,2,3-triazole-4-carboxamide; $\mathrm{Tz}_{2} \mathrm{~A}_{4}$, (2H)-1,2,3-triazole-4-carboxamide.

\section{Materials}

Azole carboxamide ribonucleoside (Fig. 13.2.2): $\mathbf{S . 1 3}\left(\mathrm{N}=\mathrm{rTz}_{2} \mathrm{~A}_{4}\right.$; Lehmkuhl et al., 1972) or $\mathbf{S . 1 4}\left(\mathrm{N}=\mathrm{rTzA}_{4}\right.$; Lehmkuhl et al., 1972)

$p$-Toluenesulfonic acid monohydrate (TsOH; Aldrich)

Tetrahydrofuran (THF), anhydrous

Trimethyl orthoformate $\left[\left(\mathrm{CH}_{3} \mathrm{O}\right)_{3} \mathrm{CH}\right.$; Aldrich], anhydrous

Methylene chloride, anhydrous (distill from phosphorus pentoxide and store over 4-A molecular sieves)

Methanol, ACS reagent grade

$5 \%$ phosphomolybdic acid solution (see recipe)

Pyridine, anhydrous

$p$-Toluenesulfonyl chloride ( $\mathrm{TsCl}$ )

4- $N, N$-Dimethylaminopyridine (DMAP)

Ethyl acetate, ACS reagent grade

200- to 400-mesh silica gel 60

Hexane, ACS reagent grade

Phosphorus pentoxide $\left(\mathrm{P}_{2} \mathrm{O}_{5}\right)$

Acetonitrile, anhydrous

Nucleoside

Phosphorylation and Related Modifications

\section{2 .9}

Supplement 16 
Argon

Tris(tetra- $n$-butylammonium) hydrogen pyrophosphate (see Basic Protocol 1)

Deuterated acetonitrile (Aldrich)

Dowex AG 50W-X8 cation-exchange resin (100 to 200 mesh, Bio-Rad)

$1 \mathrm{M} \mathrm{HCl}$

$1 \mathrm{M}$ and concentrated $(28 \%)$ ammonium hydroxide $\left(\mathrm{NH}_{4} \mathrm{OH}\right)$

Trifluoroacetic acid (TFA)

Mobile phase A: 0.1 M potassium phosphate buffer, pH 6.0 (APPENDIX 2A) containing $4 \mathrm{mM}$ tetrabutylammonium dihydrogenphosphate (TBAP, Aldrich; added from a $1.0 \mathrm{M}$ stock)

Mobile phase B: 70:30 (v/v) mobile phase A/methanol, $\mathrm{pH} 7.2$

CF11 fibrous cellulose (Whatman)

50,100 , and $500 \mathrm{mM}$ ammonium bicarbonate $\left(\mathrm{NH}_{4} \mathrm{HCO}_{3}\right)$ solutions

(no $\mathrm{pH}$ adjustment)

$1 \%(\mathrm{w} / \mathrm{v})$ sulfosalicylic solution (see recipe)

$0.2 \%(\mathrm{w} / \mathrm{v})$ ferric chloride solution (see recipe)

Triethanolamine

Magnesium chloride hexahydrate $\left(\mathrm{MgCl} \cdot 6 \mathrm{H}_{2} \mathrm{O}\right)$

Potassium chloride $(\mathrm{KCl})$

Sodium phosphoenolpyruvate monohydrate (PEP; Sigma)

$1 \mathrm{M}$ sodium hydroxide $(\mathrm{NaOH})$

Pyruvate kinase (see recipe)

Ammonium bicarbonate

Ammonium hydroxide, concentrated

Affi-Gel 601 boronate affinity gel (Bio-Rad)

$1 \mathrm{M}$ ammonium bicarbonate $\left(\mathrm{NH}_{4} \mathrm{HCO}_{3}\right), \mathrm{pH} 8.5$ (see recipe)

Carbon dioxide source (e.g., dry ice)

Q Sepharose FF anion-exchange resin (Bio-Rad)

$1 \mathrm{M}$ potassium chloride $(\mathrm{KCl})$

20-mL one-neck round-bottom flasks, oven dried

TLC plates:

Silica gel $60 \mathrm{~F}_{254}$ polyester-backed TLC plates (Aldrich)

Cellulose TLC plates (EM Science)

Heat gun

254-nm UV light lamp

Rotary evaporator with adjustable temperature and water aspirator

$2 \times 25-\mathrm{cm}, 2.5 \times 5-\mathrm{cm}, 2.5 \times 10-\mathrm{cm}, 2.5 \times 20-\mathrm{cm}$, and $2.5 \times 25-\mathrm{cm}$

chromatography columns

Vacuum desiccator

250-mL round-bottom flask

Lyophilizer

HPLC system (e.g., Beckman System Gold) including:

128 Solvent Module

166 Detector set at $230 \mathrm{~nm}$

$25-\mathrm{cm} \times 4.6-\mathrm{mm} \times 5-\mu \mathrm{m}$-i.d. Supelcosil LC-18-T column

1-L beaker

TLC sprayer (Analtech)

25-mm-diameter, 0.2- $\mu \mathrm{m}$ nylon syringe filter (Fisher)

Peristaltic pump

Medium-pressure liquid chromatography (MPLC) system (e.g., ISCO LC system) with following equipment:

Model 2360 gradient programmer 
Model 2350 HPLC pump

$\mathrm{V}^{4}$ variable wavelength absorbance detector

Additional reagents and equipment for thin-layer chromatography (TLC, APPENDIX $3 D$ ), column chromatography (APPENDIX $3 E$ ), and ${ }^{1} \mathrm{H}$ NMR, ${ }^{13} \mathrm{C}$ NMR, ${ }^{31} \mathrm{P}$ NMR, and ESI-MS

\section{Protect 2',3'-hydroxyl groups of $r \mathrm{TzA}_{4}$ (S.13) and prepare 5'-tosylate (S.15)}

1. Add $250 \mathrm{mg}(1.0 \mathrm{mmol}) \mathrm{rTz}_{2} \mathrm{~A}_{4}$ azole carboxamide ribonucleoside (S.13) and 210 $\mathrm{mg}(1.1 \mathrm{mmol}) \mathrm{TsOH}$ to a $20-\mathrm{mL}$ one-neck round-bottom flask equipped with a magnetic stir bar.

2. Add $5 \mathrm{~mL}$ anhydrous THF and $0.55 \mathrm{~mL}(5.0 \mathrm{mmol})$ trimethyl orthoformate to the flask and stir the reaction mixture at room temperature.

The suspension becomes clear after $20 \mathrm{~min}$.

3. Monitor the progress of the reaction by analytical TLC (APPENDIX 3D) as follows:

a. Withdraw a small sample using a capillary tube and spot on a silica gel $60 \mathrm{~F}_{254}$ polyester-backed TLC plate.

b. Develop the TLC plate in 10:1 (v/v) methylene chloride/methanol.

c. Visualize by dipping the plate into $5 \%$ phosphomolybdic acid solution and heating with a heat gun.

The starting material and product appear as blue or dark blue spots on a green background.

4. When TLC indicates the reaction is complete $(\sim 2 \mathrm{hr})$, add $0.5 \mathrm{~mL}$ pyridine to the solution.

5. Remove the solvent using a rotary evaporator equipped with a water aspirator.

6. Dissolve the residue in $5 \mathrm{~mL}$ anhydrous methylene chloride.

7. Add $230 \mathrm{mg}(1.2 \mathrm{mmol}) \mathrm{TsCl}$ and $160 \mathrm{mg}(1.3 \mathrm{mmol})$ DMAP and stir the reaction mixture at room temperature.

8. Monitor the progress of the reaction by TLC on a silica gel plate in 10:1 (v/v) ethyl acetate/methanol as described in step 3.

9. When TLC indicates the reaction is complete ( $\sim 24 \mathrm{hr})$, remove the magnetic stir bar from the flask.

10. Pack $30 \mathrm{~g}$ of 200 - to 400 -mesh silica gel 60 into a $2 \times 25-\mathrm{cm}$ chromatography column in $1: 1(\mathrm{v} / \mathrm{v})$ hexanes/ethyl acetate.

11. Load the reaction mixture on top of the silica gel column and elute with 10:9:1 (v/v/v) hexane/ethyl acetate/methanol.

12. Collect 10-mL fractions and check by silica gel TLC as described in step 3 .

13. Combine fractions containing product and evaporate to dryness.

14. Dry the product in a desiccator over phosphorus pentoxide in vacuo.

Flash chromatography yields $310 \mathrm{mg}(70 \%)$ of $\mathbf{S . 1 5}$ as white solid. ${ }^{1} \mathrm{H}$ NMR for diastereomer (DMSO-d, $300 \mathrm{MHz}): 8.09,8.10(1 \mathrm{H}, \mathrm{s}), 7.89(1 \mathrm{H}, \mathrm{s}), 7.61(1 \mathrm{H}, \mathrm{s}), 7.58(2 \mathrm{H}$, d), $7.35(2 \mathrm{H}, d), 6.33(1 \mathrm{H}, \mathrm{d}, \mathrm{J}=6.0 \mathrm{~Hz}), 6.03,6.14(1 \mathrm{H}, \mathrm{s}), 5.20(2 \mathrm{H}, \mathrm{m}), 4.49(1 \mathrm{H}, \mathrm{m})$, $4.06(2 \mathrm{H}, \mathrm{m}), 3.21,3.29(3 \mathrm{H}, \mathrm{s}), 2.39(3 \mathrm{H}, \mathrm{s}) . \mathrm{MS}(\mathrm{ESI}): 463[\mathrm{M}+\mathrm{Na}]^{+}$. Anal. calcd. for $\mathrm{C}_{17} \mathrm{H}_{20} \mathrm{O}_{8} \mathrm{~N}_{4} \mathrm{~S}: \mathrm{C}$ 46.36, $\mathrm{H}$ 4.58, $\mathrm{N}$ 12.72; found: C 46.74, H 4.55, N 12.61 .

Characterization data for $\mathbf{S . 1 6}$ can be found in Wu et al. (2003).

Nucleoside

Phosphorylation and Related Modifications

13.2.11 
Prepare $2^{\prime}, 3^{\prime}$-protected diphosphate

15. Add $350 \mathrm{mg}(0.8 \mathrm{mmol}) \mathbf{S . 1 5}$ to an oven-dried 20 -mL one-neck round-bottom flask.

16. Coevaporate $\mathbf{S . 1 5}$ with $5 \mathrm{~mL}$ anhydrous acetonitrile three times.

17. Evacuate and flush the flask with argon.

18. Add $1.4 \mathrm{~g}$ ( $1.6 \mathrm{mmol})$ tris(tetra- $n$-butylammonium) hydrogen pyrophosphate to the flask.

19. Transfer $0.5 \mathrm{~mL}$ anhydrous acetonitrile into the reaction flask and stir the reaction mixture at room temperature under argon.

20. Monitor the progress of the reaction by ${ }^{1} \mathrm{H}$ NMR as follows:

a. Withdraw $50 \mu \mathrm{L}$ reaction mixture and dilute with $0.5 \mathrm{~mL}$ deuterated acetonitrile.

b. Transfer the sample to a dried NMR tube and acquire a ${ }^{1} \mathrm{H}$ NMR spectrum.

c. Monitor the progress of the reaction by the change in the ${ }^{1} \mathrm{H}$ NMR spectrum between 7 and 9 ppm, where the tosylate moiety appears as an $\mathrm{AA}^{\prime} \mathrm{XX}^{\prime}$ spin system.

The four-line pattern for the tosylate moves upfield by 0.1 to 0.2 ppm upon conversion to the tosylate anion.

TLC is not suitable for monitoring the progress of the reactions because the tetra-n-butylammonium salt does not give a well-defined spot.

21. When ${ }^{1} \mathrm{H}$ NMR indicates the reaction is complete ( $\sim 2$ days), dilute the reaction mixture with $5 \mathrm{~mL}$ water.

22. Pack Dowex AG 50W-X8 cation-exchange resin in water into a $2.5 \times 10-\mathrm{cm}$ column. Transform the cation-exchange resin to the ammonium form by washing the column with $150 \mathrm{~mL}$ ( 3 column volumes) of the following solutions in sequence:

\section{$1 \mathrm{M} \mathrm{HCl}$ \\ $\mathrm{H}_{2} \mathrm{O}$ $1 \mathrm{M} \mathrm{NH}_{4} \mathrm{OH}$ \\ $\mathrm{H}_{2} \mathrm{O}$.}

23. Load the solution from step 21 onto the column and elute with $100 \mathrm{~mL}$ ( 2 column volumes) of deionized water. Collect the eluent in a $250-\mathrm{mL}$ round-bottom flask.

24. Lyophilize the solution to dryness.

Deprotect 2',3'-hydroxyl groups

25. Dissolve the resulting solid in $20 \mathrm{~mL}$ deionized water and adjust the $\mathrm{pH}$ to 2.0 with TFA.

26. Stir the solution $2 \mathrm{hr}$ at room temperature.

27. Monitor the progress of the reaction by analytical HPLC. Take $2-\mu \mathrm{L}$ aliquots, dilute with mobile phase A, and run on a Supelcosil LC-18-T column at a flow rate of 1.5 $\mathrm{mL} / \mathrm{min}$ using the following gradient conditions:

$0 \%$ to $100 \%$ mobile phase $\mathrm{B}$ over $10 \mathrm{~min}$

$100 \%$ mobile phase $\mathrm{B}$ for 8 min

$100 \%$ to $0 \%$ mobile phase B over 2 min.

The retention times of the $2^{\prime}, 3^{\prime}$-protected diphosphate should be 12.9 and 13.4 min (mixture of diastereomers); the retention times of the acid deprotection intermediate should be 10.7 and 11.1 min (mixture of 2'- and 3'-formate).

For care of the column, see Basic Protocol 1, step 44. 
28. When HPLC indicates that hydrolysis is complete $(\sim 3 \mathrm{hr})$, adjust the $\mathrm{pH}$ of the solution to 8.5 with $1 \mathrm{M} \mathrm{NH}_{4} \mathrm{OH}$.

29. Stir the solution at room temperature and monitor the progress of the reaction by HPLC.

The retention time of the fully deprotected diphosphate $\mathrm{S.17}$ should be $8.6 \mathrm{~min}$.

30. When HPLC indicates that deprotection is complete $(\sim 2 \mathrm{hr})$, lyophilize the reaction mixture to dryness.

Purify S.17

31. Pack a Whatman CF11 fibrous cellulose column as follows:

a. Mix $500 \mathrm{~mL}$ (dry volume) CF11 fibrous cellulose power with $350 \mathrm{~mL}$ water in a $1-\mathrm{L}$ beaker by vigorous stirring with a glass rod.

b. Slurry-pack the cellulose into a $2.5 \times 25-\mathrm{cm}$ chromatography column.

c. Wash the column with $300 \mathrm{~mL}$ water, $300 \mathrm{~mL}$ acetonitrile, and $300 \mathrm{~mL}$ of 1:1 (v/v) acetonitrile/water in sequence.

d. Equilibrate the column with $300 \mathrm{~mL}$ of 7:3:2 (v/v/v) acetonitrile/100 mM ammonium bicarbonate/concentrated (28\%) ammonium hydroxide.

32. Extract the solid obtained from step 30 with $5 \mathrm{~mL}$ of the same acetonitrile/ammonium bicarbonate/ammonium hydroxide buffer. Pellet the precipitate.

The product is soluble in the buffer and the white precipitate formed is excess inorganic pyrophosphate.

33. Load the sample solution onto the column and elute with the same buffer by flash chromatography, collecting 10-mL fractions.

34. Analyze every second fraction on a cellulose TLC plate as follows:

a. Spot the sample on the cellulose TLC plate and develop in 7:3:2(v/v/v) acetonitrile/100 $\mathrm{mM}$ ammonium bicarbonate/concentrated ammonium hydroxide.

b. Spray the plate with $1 \%$ sulfosalicylic acid solution until thoroughly wetted but not dripping, and allow to air dry 5 min.

c. Lightly spray $0.2 \%$ ferric chloride solution onto the plate and visualize the spots. When visualized by sulfosalicylic acidfferric chloride spray, phosphate-containing compounds appear as white spots on a pink background. A second light spray with ferric chloride may be necessary to make the spots pronounced $\left(R_{f}=0.30\right.$ for $\left.S .17\right)$.

35. Combine the fractions containing product and remove acetonitrile using a rotary evaporator with the bath temperature set below $30^{\circ} \mathrm{C}$.

36. Lyophilize the resulting aqueous solution to dryness.

37. Confirm the product by ${ }^{1} \mathrm{H}$ NMR, ${ }^{13} \mathrm{C}$ NMR, ${ }^{31} \mathrm{P}$ NMR, and ESI-MS.

Flash cellulose chromatography yields $254 \mathrm{mg}$ (70\%) $\mathrm{S.17}$ as a fluffy white powder. ${ }^{1} \mathrm{H}$ $\operatorname{NMR}\left(\mathrm{D}_{2} \mathrm{O}, 300 \mathrm{MHz}\right): 8.01(1 \mathrm{H}, \mathrm{s}), 5.98(1 \mathrm{H}, \mathrm{d}, \mathrm{J}=3.6 \mathrm{~Hz}), 4.49(1 \mathrm{H}, \mathrm{m}), 4.18(1 \mathrm{H}, \mathrm{m})$, $3.93(2 \mathrm{H}, \mathrm{m}) .{ }^{13} \mathrm{CNMR}\left(\mathrm{D}_{2} \mathrm{O}, 75 \mathrm{MHz}\right): 164.3,143.2,136.5,95.6,84.4,74.6,70.7,65.4$. ${ }^{31} \mathrm{P} N M R\left(D_{2} O, 121 \mathrm{MHz}\right):-7.78\left(d, J_{p, p}=20.6 \mathrm{~Hz}\right),-10.79\left(d, J_{p, p}=20.6 \mathrm{~Hz}\right) . \mathrm{HRMS}$ (ESI): calcd. for $\mathrm{C}_{8} \mathrm{H}_{15} \mathrm{~N}_{4} \mathrm{O}_{11} \mathrm{P}_{2} 405.0213[\mathrm{M}+\mathrm{H}]^{+}$; found 405.0208.

Characterization data for $\mathbf{S . 1 8}$ can be found in Wu et al. (2003).

Nucleoside Phosphorylation and Related Modifications

\subsubsection{3}

Supplement 16 
38. Dissolve the following in $8 \mathrm{~mL}$ deionized water:

$154 \mathrm{mg}(0.83 \mathrm{mmol})$ triethanolamine

$34.5 \mathrm{mg}(0.17 \mathrm{mmol}) \mathrm{MgCl} \cdot 6 \mathrm{H}_{2} \mathrm{O}$

$50 \mathrm{mg}(0.67 \mathrm{mmol}) \mathrm{KCl}$

$180 \mathrm{mg}(0.4 \mathrm{mmol}) \mathbf{S . 1 7}$

$152 \mathrm{mg}(0.8 \mathrm{mmol})$ PEP.

39. Adjust the $\mathrm{pH}$ to 7.6 with $1 \mathrm{M} \mathrm{NaOH}$, then add deionized water to adjust the final volume to $10 \mathrm{~mL}$.

40. Add $16 \mu \mathrm{L}(40 \mathrm{U})$ pyruvate kinase and incubate the reaction mixture at $37^{\circ} \mathrm{C}$.

41. Monitor the progress of the reaction by analytical HPLC as described in step 27.

Retention times are $\sim 9.1$ and $\sim 10.6$ min for $r T_{z} A_{4} D P$ and $r T z A_{4} T P$, respectively.

42. When HPLC indicates complete conversion of $\mathbf{S . 1 7}$ to triphosphate $\mathbf{S . 1 9}(\sim 4 \mathrm{hr})$, add $790 \mathrm{mg}$ ammonium bicarbonate to the solution.

43. Adjust the $\mathrm{pH}$ to 8.5 with concentrated (28\%) ammonium hydroxide and filter the mixture through a 25 -mm-diameter, $0.2-\mu \mathrm{m}$ nylon syringe filter.

\section{Purify S.19 on a boronate affinity gel column}

44. Mix $5 \mathrm{~g}$ Affi-Gel 601 boronate affinity gel with water and slurry-pack into a $2.5 \times$ 5-cm column.

45. Equilibrate with $100 \mathrm{~mL}$ of $1 \mathrm{M}$ ammonium bicarbonate, $\mathrm{pH} 8.5$.

46. Load the sample solution from step 43 onto the column using a peristaltic pump at 1 $\mathrm{mL} / \mathrm{min}$.

Alternatively, sample loading and column elution can be done by gravity.

47. Elute the column with $90 \mathrm{~mL}$ of $1 \mathrm{M}$ ammonium bicarbonate using a peristaltic pump at $1 \mathrm{~mL} / \mathrm{min}$ with $\mathrm{UV}$ detention at $230 \mathrm{~nm}$.

Excess PEP and enzyme reaction buffer are eluted out in this step.

48. Elute the column with deionized water at $2 \mathrm{~mL} / \mathrm{min}$, collecting $5-\mathrm{mL}$ fractions with UV detection at $230 \mathrm{~nm}$.

S.19 is eluted with water.

49. Combine all the fractions containing $\mathbf{S . 1 9}$ and bubble carbon dioxide into the solution until the $\mathrm{pH}$ reaches 7.2.

Carbon dioxide may be conveniently generated from dry ice in a filtering flask with a stopper and a side hose outlet.

50. Lyophilize the solution to dryness. Resuspend in $50 \mathrm{~mL}$ water and adjust to $\mathrm{pH} 7.2$ with carbon dioxide. Repeat lyophilization.

Two or three lyophilization cycles may be required to completely remove excess ammonium bicarbonate.

Chemoenzymatic

Preparation of Nucleoside

Triphosphates

13.2.14 
Purify S.19 on a $Q$ Sepharose FF anion-exchange column

51. Pack a $2.5 \times 20-\mathrm{cm}$ Q Sepharose FF anion-exchange column and elute with the following using a peristaltic pump at $5 \mathrm{~mL} / \mathrm{min}$ :

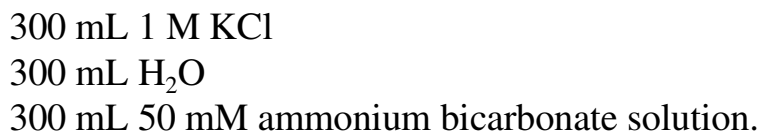

52. Connect the column to an MPLC system equipped with a programmable gradient pump system and a UV detector.

53. Dissolve the solid from step 50 in $10 \mathrm{~mL}$ of $50 \mathrm{mM}$ ammonium bicarbonate solution and load the sample solution onto the column.

54. Elute the column with a linear gradient from $50 \mathrm{mM}$ ammonium bicarbonate to 500 $\mathrm{mM}$ ammonium bicarbonate over $2 \mathrm{hr}$ at a flow rate of $5 \mathrm{~mL} / \mathrm{min}$ with $\mathrm{UV}$ detection at $230 \mathrm{~nm}$.

55. Analyze the appropriate fractions by HPLC as described in step 27.

56. Combine fractions containing $\mathbf{S . 1 9}$ and lyophilize to dryness.

57. Confirm the product by ${ }^{1} \mathrm{H}$ NMR, ${ }^{13} \mathrm{C}$ NMR, ${ }^{31} \mathrm{P}$ NMR, and ESI-MS.

Purification yields $78 \mathrm{mg}$ (72\%) $\mathrm{S.19}$ (ammonium salt) as a white fluffy solid. ${ }^{1} \mathrm{H}$ NMR $\left(\mathrm{D}_{2} \mathrm{O}, 300 \mathrm{MHz}\right): 8.05(1 \mathrm{H}, \mathrm{s}), 6.02(1 \mathrm{H}, \mathrm{d}, \mathrm{J}=3.9 \mathrm{~Hz}), 4.24(1 \mathrm{H}, \mathrm{m}), 4.03(2 \mathrm{H}, \mathrm{m}) .{ }^{13} \mathrm{C}$ $\mathrm{NMR}\left(\mathrm{D}_{2} \mathrm{O}, 75 \mathrm{MHz}\right): 163.9,142.8,136.1,95.1,84.1,74.1,70.4,65.3 .{ }^{31} \mathrm{P} \mathrm{NMR}\left(\mathrm{D}_{2} \mathrm{O}\right.$, $121 \mathrm{MHz}):-9.11\left(\mathrm{~d}, J_{p, p}=19.4 \mathrm{~Hz}\right),-11.18\left(\mathrm{~d}, J_{p, p}=19.4 \mathrm{~Hz}\right),-22.56\left(t, J_{p, p}=19.4 \mathrm{~Hz}\right)$. HRMS (ESI): calcd. for $\mathrm{C}_{8} \mathrm{H}_{16} \mathrm{~N}_{4} \mathrm{O}_{14} \mathrm{P}_{3} 484.9876[\mathrm{M+H}]^{+}$; found 484.9869 .

Characterization data for $\mathbf{S . 2 0}$ can be found in Wu et al. (2003).

\section{REAGENTS AND SOLUTIONS}

Use deionized, distilled water in all recipes and protocol steps. For common stock solutions, see APPENDIX 2A; for suppliers, see SUPPLIERS APPENDIX.

\section{Ammonium bicarbonate solution, $1 \mathrm{M}, \mathrm{pH} 8.5$}

Dissolve $39.5 \mathrm{~g}$ ammonium bicarbonate $\left(\mathrm{NH}_{4} \mathrm{HCO}_{3}\right)$ in $400 \mathrm{~mL}$ water and adjust to $\mathrm{pH} 8.5$ with concentrated (28\%) ammonium hydroxide $\left(\mathrm{NH}_{4} \mathrm{OH}\right)$. Dilute to $500 \mathrm{~mL}$ with water. Make fresh every time.

Ferric chloride solution, $0.2 \%(w / v)$

Dissolve $0.2 \mathrm{~g}$ ferric chloride in $100 \mathrm{~mL}$ of $4: 1(\mathrm{v} / \mathrm{v})$ ethanol/water. Use within $6 \mathrm{hr}$.

\section{Nucleoside diphosphate kinase}

Purchase nucleoside diphosphate kinase (EC 2.7.4.6; from baker's yeast; Sigma) as a lyophilized powder. Reconstitute with water to $2 \mathrm{U} / \mu \mathrm{L}$. Store indefinitely at $-20^{\circ} \mathrm{C}$.

\section{Phosphomolybdic acid solution, 5\% (w/v)}

Dissolve $25 \mathrm{~g}$ of phosphomolybdic acid in $500 \mathrm{~mL}$ of $95 \%(\mathrm{v} / \mathrm{v})$ ethanol. Store indefinitely in an amber reagent bottle at room temperature.

\section{Pyruvate kinase}

Purchase pyruvate kinase (EC 2.7.1.40; Type VII from rabbit muscle; Sigma) at 2.5 $\mathrm{U} / \mu \mathrm{L}$ in $50 \%$ glycerol containing $0.01 \mathrm{M}$ phosphate, $\mathrm{pH}$ 7.0. Store indefinitely at $4^{\circ} \mathrm{C}$.

Nucleoside Phosphorylation and Related Modifications

\subsubsection{5}

Supplement 16 
Sulfosalicylic solution, $1 \%(w / v)$

Dissolve $1.0 \mathrm{~g}$ sulfosalicylic acid in $100 \mathrm{~mL}$ of 3:2 (v/v) ethanol/water. Use within $6 \mathrm{hr}$.

\section{COMMENTARY}

\section{Background Information}

\section{Synthetic modified nucleobases as alternative substrates for DNA and RNA polymerases}

Synthetic modified nucleobases designed to pair in unusual ways with the natural nucleic acid base have many potential applications in nucleic acid biochemistry, ranging from biochemical tools for probing nucleic acid structures or protein-nucleic acid interactions to tools for re-engineering DNA and ultimately proteins. One class of materials of particular interest is the azole carboxamide nucleobases. Designed as universal bases, they have the interesting property of displaying multiple conformations and can mimic different sets of natural bases in the context of DNA replication. The variation in electronic distribution in these compounds offers a range of hydrogen-bonding features (Hoops et al., 1997; Zhang et al., 1998). The azole carboxamide deoxyribonucleoside triphosphates (see Fig. 13.2.1) are used as alternate substrates for DNA polymerase to probe enzyme fidelity during DNA replication; similarly, the azole carboxamide ribonucleoside triphosphates (see Fig. 13.2.2) can be used as alternate substrates for RNA polymerase to probe structure and function of RNA polymerase.

\section{Synthesis of nucleoside triphosphates}

The general utility of the "one-pot threestep" procedures for the synthesis of purine or pyrimidine nucleoside triphosphates has been established (Ludwig, 1981; Mishra and Broom, 1991; Burgess and Cook, 2000). Other multistep methods that rely on activated nucleoside monophosphates have also had long-standing application for these more standard nucleotides (Moffatt and Khorama, 1961; Hoard and Ott, 1965; Simoncsits and Tomasz, 1975; Tomasz et al., 1978). These methods involve the use of the Yoshikawa procedure or a variation of the Yoshikawa procedure which employs conditions for selective $5^{\prime}$-phosphorylation with phosphorus oxychloride as the primary donor (Yoshikawa et al., 1967). This reactive electrophilic phosphorus reagent presents limitations with many heterocycles, such as azole carbox- amides, since attack at the carboxamide leads to side reactions. Alternative strategies that use other electrophilic $P^{3}$ or $P^{5}$ reagents are equally limiting because many heterocycles are susceptible to addition reactions with these reagents (van Boom et al., 1975; Ludwig and Eckstein, 1989).

Enzyme-catalyzed synthesis of nucleoside triphosphates has proven to be a general method for a variety of purine and pyrimidine nucleoside analogs (Wong et al., 1983; Simon et al., 1988). Nucleoside diphosphate kinase (NDPK) catalyzes the transfer of the $\gamma$-phosphate from a nucleoside triphosphate to a nucleoside diphosphate. The enzyme is remarkably nonspecific with regard to the nucleotide substrate; it uses di- and triphosphate nucleotides with either deoxyribose or ribose and any of the natural purine and pyrimidine bases (Ratliff et al., 1964; Mourad and Parks, 1966). A number of the unnatural purine and pyrimidine nucleotide analogs can also serve as substrates (Miller et al., 1992; Kamiya and Kasai, 1999). The authors' experiments with NDPK show that the azole carboxamide nucleoside diphosphates are substrates for NDPK. The reaction equilibrium offers a general method for the preparation of nucleoside triphosphates from diphosphates. In the case of the azole carboxamide deoxyribonucleoside diphosphates, incorporation of an ATP regeneration system using phosphoenolpyruvate (PEP) and pyruvate kinase allows for efficient conversion to the triphosphates (Hirschbein et al., 1982). In the case of azole carboxamide ribonucleoside diphosphates, preliminary studies show that NPDK and dATP coupled with dATP regeneration by pyruvate kinase and PEP could efficiently convert azole carboxamide nucleoside diphosphates to triphosphates. However, pyruvate kinase was later found to directly catalyze the phosphorylation of the azole carboxamide ribonucleoside diphosphates, allowing a simplified system to complete the transformation.

Most biochemical applications of nucleoside triphosphates require a high degree of purity, especially with respect to other contaminating nucleotides. An efficient purification procedure was optimized for the desired nucleoside triphosphates following enzymatic
Preparation Nucleoside

Triphosphates

13.2.16 
phosphorylation. In the case of the deoxyribonucleoside triphosphate synthesis, separation from ATP is necessary, which is not readily achieved by conventional ion-exchange chromatography. Boronate affinity gel has been used to separate ribonucleoside 5 -phosphates from deoxyribonucleotides due to the formation of a complex between the borate group and cis-diol of the ribonucleoside (Schott, 1972; Schott et al., 1973). Passing the enzyme phosphorylation mixture through the boronate affinity gel at high $\mathrm{pH}$ gives efficient separation of the resulting azole carboxamide deoxyribonucleoside triphosphate from ATP. Purification of the azole carboxamide ribonucleoside triphosphate using boronate affinity gel is also more straightforward.

The methods described in this unit for chemoenzymatic preparation of nucleoside triphosphates extend the use of nucleoside diphosphate synthesis (Davisson et al., 1987) to a general route for nucleoside triphosphate synthesis. It is likely that this strategy will be applicable as a general protocol for preparation of triphosphates of a wide variety of base- and sugar-modified nucleoside analogs.

\section{Critical Parameters and Troubleshooting}

Since the nucleoside diphosphates and triphosphates prepared in these procedures are both acid and base labile, the $\mathrm{pH}$ of the product-containing solution must stay between 2.0 and 9.0, and all products must be stored at $-20^{\circ} \mathrm{C}$.

Preparation of nucleoside diphosphates. High concentrations of tosylate and pyrophosphate are necessary for the displacement reaction to proceed at reasonable rates. Cellulose TLC is critical for detecting diphosphate-containing fractions after flash cellulose chromatography. Using EM Science TLC plates and following the procedure given for staining the plates will give the best results.

Enzyme phosphorylation. When constructing the azole carboxamide deoxyribonucleoside triphosphates, it is very important to completely convert excess PEP to pyruvate by adding ADP after phosphorylation of the diphosphate is complete (see Basic Protocol 1). Excess PEP interferes with the final purification of triphosphate on a Q Sepharose FF anion-exchange column. For ribonucleosides, the excess PEP is easily separated from the triphosphate by boronate affinity gel chromatography. The PEP passes through the column using $1 \mathrm{M}$ ammonium bicarbonate, and the triphosphate is then eluted using water.

Purification of triphosphates. It is necessary to use a slow flow rate $(1 \mathrm{~mL} / \mathrm{min})$ for the boronate affinity gel column since faster flow rates may not allow complete binding of the ribonucleotides to the boronate affinity gel.

Synthesis of alternate nucleoside triphosphates. Synthesis of the other azole carboxamide deoxyribonucleoside triphosphates shown in Fig. 13.2 .1 (i.e., S.11 and S.12) can be accomplished using the exact conditions and quantities presented in the steps of Basic Protocol 1. Simple adjustments to the reaction times for the tosylation and diphosphate displacement are needed, and different chromatography solvents are used to purify the $\mathbf{S . 5}$ and S.6 tosylates; these adjustments can be found in Wu et al. (2003). For synthesis of the other azole carboxamide ribonucleoside triphosphate shown in Fig. 13.2.2 (S.20), there is one major modification with regard to the reaction conditions for synthesis of $2^{\prime}, 3^{\prime}$-protected $5^{\prime}$ tosylate $\mathbf{S . 1 6}$ from nucleoside $\mathbf{S . 1 4}$; this modification is also detailed in $\mathrm{Wu}$ et al. (2003). Preparation of the nucleoside diphosphate S.18 and enzyme phosphorylation to $\mathbf{S . 2 0}$ can be accomplished using the exact conditions and quantities presented in the steps of Basic Protocol 2 .

\section{Anticipated Results}

The protocols described in this unit allow preparation of the azole carboxamide deoxyribo- and ribonucleoside triphosphates in good yields and high purity. In the first method (see Basic Protocol 1), selective tosylation of the azole carboxamide deoxyribonucleosides should give 5'-O-tosyl nucleosides in yields between $60 \%$ and $70 \%$. Preparation of nucleoside diphosphates from $5^{\prime}$-O $O$-tosyl nucleosides should give yields between $70 \%$ and $90 \%$. Enzyme phosphorylation and subsequent purification should give deoxyribonucleoside triphosphates in yields between 58\% and 89\%.

In the second method (see Basic Protocol 2), protection of the $2^{\prime}, 3^{\prime}$-hydroxyl groups of the azole carboxamide ribonucleosides and subsequent tosylation should give 5 '- $O$-tosyl nucleosides in $52 \%$ to $70 \%$ yields. Diphosphate displacement and deprotection of $2^{\prime}, 3^{\prime}$-hydroxyl groups should give ribonucleoside diphosphates in yields between $66 \%$ and $70 \%$. Enzyme phosphorylation and subsequent purification should give ribonucleoside triphosphates in $\sim 70 \%$ yield.
Nucleoside Phosphorylation and Related Modifications

\subsubsection{7}

Supplement 16 


\section{Time Considerations}

In the first method (see Basic Protocol 1), preparation of $5^{\prime}$ - $O$-tosyl nucleosides may take 2 to 4 days ( 4 days for S.4, or 1 to 2 days for the alternate tosylates $\mathbf{S . 5}$ and S.6). Preparation of nucleoside diphosphates should take 3 to 4 days for the displacement reaction, cation exchange, and cellulose chromatography. Enzyme phosphorylation and purification of resulting triphosphates should take $\sim 7$ days to complete.

In the second method (see Basic Protocol 2), preparation of $5^{\prime}$ - $O$-tosyl nucleosides may take 3 to 4 days for protection of $2^{\prime}, 3^{\prime}$-hydroxyl groups and tosylation. Preparation of nucleoside diphosphates requires 5 days for the displacement reaction, cation exchange, deprotection of $2^{\prime}, 3^{\prime}$-hydroxyl groups, and cellulose chromatography. Enzyme phosphorylation and purification of resulting triphosphates needs $\sim 6$ days to complete.

\section{Literature Cited}

Burgess, K. and Cook, D. 2000. Syntheses of nucleoside triphosphates. Chem. Rev. 100:20472060.

Davisson, V.J., Davis, D.R., Dixit, V.M., and Poulter, C.D. 1987. Synthesis of nucleotide $5^{\prime}$-diphosphates from 5'-O-tosyl nucleosides. J. Org. Chem. 52:1794-1801.

Hirschbein, B.L., Mazenod, F.P., and Whitesides, G.M. 1982. Synthesis of phosphoenolypyruvate and its use in ATP cofactor regeneration. J. Org. Chem. 47:3765-3766.

Hoard, D.E. and Ott, D.G. 1965. Conversion of mono- and oligodeoxyribonucleotides to $5^{\prime}$ triphosphates. J. Am. Chem. Soc. 87:1785-1788.

Hoops, G.C., Zhang, P., Johnson, W.T., Paul, N., Bergstrom, D.E., and Davisson, V.J. 1997. Template directed incorporation of nucleotide mixtures using azole-nucleobase analogs. Nucl. Acids Res. 25:4866-4871.

Kamiya, H. and Kasai, H. 1999. Preparation of 8-hydroxy-dGTP and 2-hydroxy-dATP by a phosphate transfer reaction by nucleosidediphosphate kinase. Nucleos. Nucleot. Nucl. Acids 18:307-310.

Lehmkuhl, F.A., Witkowski, J.T., and Robins, R.K. 1972. Synthesis of 1,2,3-triazole nucleosides via the acid-catalyzed fusion procedure. J. Heterocyclic Chem. 9:1195-1201.

Ludwig, J. 1981. A new route to nucleoside 5'triphosphates. Acta Biochim. Biophys. Acad. Sci. Hung. 16:131-133.

Ludwig, J. and Eckstein, F. 1989. Rapid and efficient synthesis of nucleoside $5^{\prime}$-O-(1-thiotriphosphates), 5'-triphosphates and 2',3'-cyclophosphorothioates using 2-chloro-4H-1,3,2-benzodioxaphosphorin-4-one. J. Org. Chem. 54:631635.
Makabe, O., Suzuki, H., and Umezawa, S. 1977. Syntheisi of D-arabinofuranosyl and 2'-deoxy-Dribofuranosyl 1,2,3-triazolecarboxamides. Bull. Chem. Soc. Jpn. 50:2689-2693.

Miller, W.H., Daluge, S.M., Garvey, E.P., Hopkins, S., Reardon, J.E., Boyd, F.L., and Miller, R.L. 1992. Phosphorylation of carbovir enantiomers by cellular enzymes determines the stereoselectivity of antiviral activity. J. Biol. Chem. 267:21220-21224.

Mishra, N.C. and Broom, A.D. 1991. A novel synthesis of nucleoside triphosphates. J. Chem. Soc. Chem. Comm. 1276-1277.

Moffatt, J.G. and Khorama, H.G. 1961. Nucleoside polyphosphates. $\mathrm{X}^{1}$. The synthesis and some reactions of nucleoside- $5^{\prime}$ phosphoromorpholidates and related compounds. Improved methods for the preparation of nucleoside- $5^{\prime}$ polyphosphates. J. Am. Chem. Soc. 83:649-658.

Mourad, N. and Parks, R.E. Jr. 1966. Erythrocytic nucleoside diphosphokinase. II. Isolation and kinetics. J. Biol. Chem. 241:271-278.

Ratliff, R.C., Weaver, R.H., Lardy, H.A., and Kuby, S.A. 1964. Nucleoside triphosphate-nucleoside diphosphate transphosphorylase (nucleoside diphosphokinase). I. Isolation of the crystalline enzyme from brewer's yeast. J. Biol. Chem. 239:301-309.

Schott, H. 1972. New dihydroxyboryl-substituted polymers for column-chromatographic separation of ribonucleoside-deoxyribonucleoside mixtures. Angew. Chem. Int. Ed. Engl. 11:824825.

Schott, H., Rudloff, E., Schmidt, P., Roychoudhury, R., and Kossel, H. 1973. A dihydroxyboryl-substituted methacrylic polymer for the column chromatographic separation of mononucleotides, oligonucleotides, and transfer ribonucleic acid. Biochemistry 12:932-938.

Simon, E.S., Bednarski, M.D., and Whitesides, G.M. 1988. Generation of cytidine 5'-triphosphate using adenylate kinase. Tetrahedron Lett. 29:1123-1126.

Simoncsits, A. and Tomasz, J. 1975. Nucleoside 5 '-phosphordiamidates, synthesis and some properties. Nucl. Acids Res. 2:1223-1233.

Tomasz, J., Simoncsits, A., Kajtar, M., Krug, R.M., and Shatkin, A.J. 1978. Chemical synthesis of 5 '-pyrophosphate and triphosphate derivatives of $3^{\prime}-5^{\prime}$ ApA, ApG, GpA and GpG. CD study of the effect of 5'-phosphate groups on the conformation of 3'-5' GpG. Nucl. Acids Res. 5:2945-2957.

van Boom, J.H., Crea, R., Luyten, W.C., and Vink, A.B. 1975. 2,2,2-Tribromoethyl phosphoromorpholinochloridate: A convenient reagent for the synthesis of ribonucleoside mono-, di- and triphosphates. Tetrahedron Lett. 16:2779-2782.

Witkowski, J.T., Fuertes, M., Cook, P.D., and Robins, R.K. 1975. Nucleosides of 1,2,4-triazole-3carboxamide. Synthesis of certain pentofuranosyl, deoxypentofuranosyl, and pentopyranosyl 1,2,4-triazoles. J. Carbohydr. Nucleos. Nucleot. 2:1-36.
Nucleoside

Triphosphates

13.2.18 
Wong, C.H., Haynie, S.L., and Whitesides, G.M. 1983. Preparation of a mixture of nucleoside triphosphates from yeast RNA: Use in enzymic synthesis requiring nucleoside triphosphate regeneration and conversion to nucleoside diphosphate sugars. J. Am. Chem. Soc. 105:115-117.

Wu, W., Bergstrom, D.E., and Davisson, V.J. 2003. A combination chemical and enzymatic approach for the preparation of azole carboxamide nucleoside triphosphate. J. Org. Chem. 68:38603865 .

Yoshikawa, M., Kato, T., and Takenishi, T. 1967. A novel method for phosphorylation of nucleosides to 5'-nucleotides. Tetrahedron Lett. 50:5065-5068.

Zhang, P., Johnson, W.T., Klewer, D., Paul, N., Hoops, G., Davisson, V.J., and Bergstrom, D.E. 1998. Exploratory studies on azole carboxamides as nucleobase analogs: Thermal denaturation studies on oligodeoxyribonucleotide duplexes containing pyrrole-3-carboxamide. $\mathrm{Nucl}$. Acids Res. 26:2208-2215.
Key References

Burgess and Cook, 2000. See above.

This paper gives a review on syntheses of nucleoside triphosphates.

Davisson et al., 1987. See above.

This paper describes synthesis of nucleoside diphosphates from 5'-O-tosyl nucleosides.

Wu et al., 2003. See above.

This paper describes synthesis of the azole nucleoside triphosphate and compound characterization.

Contributed by Weidong Wu, Donald

E. Bergstrom, and V. Jo Davisson

Purdue University

West Lafayette, Indiana
Nucleoside

Phosphorylation

and Related

Modifications

\subsubsection{9}

Supplement 16 